\title{
Return periods of severe hailfalls computed from hailpad data
}

\author{
Roberto Fraile ${ }^{\mathrm{a}}$, Claude Berthet ${ }^{\mathrm{b}}$, \\ Jean Dessens ${ }^{\mathrm{c}, *}$, José Luis Sánchez ${ }^{\mathrm{a}}$ \\ ${ }^{a}$ Laboratorio de Física de la Atmósfera, Universidad de León, Leon, Spain \\ ${ }^{\mathrm{b}}$ Association Nationale d'Etude et de Lutte contre les Fléaux Atmosphériques, Toulouse, France \\ ${ }^{c}$ Laboratoire d'Aérologie, UMR CNRS/UPS 5560, Université de Toulouse, Toulouse, France
}

Hail is an important economic problem in several countries, and there would be a need for climatological studies not limited to general data such as space and time frequencies of ordinary hailfalls. A large network of hailpad stations, which operated continuously in southwestern France since 1988, gives the first opportunity to compute return periods of very severe point hailfalls characterized either by the total kinetic energy of hailstones or by the diameter of the largest hailstones. The Gumbel distribution has been used to represent the probability density function of the maximum annual value of these two parameters. Preliminary results indicate that the area located just north of the central Pyrenees is three times more exposed to damaging hailfalls than the Atlantic border. The results show that the computation of an areal return period depends upon the hailpad network density, which makes data normalization necessary for inter-network comparisons. This study also offers the possibility of determining return periods of severe hailfalls at a point. As an example, a provisional estimation indicates that a hailfall with hailstones of 3-4 cm diameter occurs every 22 years at any point in the hail core region north of the Pyrenees. The hope is that this study may be progressively expanded to other European hailed regions in which similar hailpad networks are in operation.

Keywords: Hail; Hailfall; Climatology; Return period

* Corresponding author. Centre de Recherches Atmosphériques, 65300 Campistrous, France.

E-mail address: desj@aero.obs-mip.fr (J. Dessens). 


\section{Introduction}

Every year, the "Association Internationale des Assureurs contre la Grêle" publishes the technical results of the crop hail insurance industry in about 20 countries of the world. In Europe, Spain is the leader for the amount of crop losses paid by the insurers, followed in this order by Italy, France, Germany, Switzerland, etc. The mean annual losses in Europe for the 1996-2000 period amount to 860 million Euros (ME), and this value does not include the non-insured crop losses. Moreover, damages to urban properties and cars are not considered in this evaluation, although they are in some cases much larger than crop losses. As a famous example, the Munich storm of 12 July, 1984 produced around $600 \mathrm{ME}$ of damage (Hohl et al., 2002).

Despite the economic impact of hail, the climatology of this phenomenon is scarce. For France, Plumandon (1901) made a pioneering work in compiling the insurance data for the 1873-1892 period, and he found that hail was concentrated around a median line going from the central Pyrenees to Switzerland. Genève (1961) used data of the French meteorological office and compiled various statistics on hail days, hailfall duration, and hailstone diameters. He also reported several observations on geographical effects and small scale variations of hailfalls. At the turn of the 1970s, a dense network of hailpads was operated in the region north to Montpellier, but the results have only occasionally appeared in unpublished reports from the Groupement National d'Etude des Fléaux Atmosphériques (GNEFA). More recently, Vinet (2000) related data from the hail insurance and from the hailpad networks of the Association Nationale d'Etude et de Lutte contre les Fléaux Atmosphériques (ANELFA) and Association Climatologique de la Moyenne Garonne (ACMG). The main results of this exhaustive study are reported in Vinet (2001), including what seems to be the most reliable map of hail risk in France.

A few other climatological studies were also made in Europe, mainly in Switzerland (Admirat et al., 1985) and Spain (Fraile et al., 1999), where hailpad networks have been operated for a few years, and in Italy (Giaiotti et al., 2001), where a dense hailpad network is still in operation. However, it is difficult to compare hail severity in these different countries, either because the measurement periods were too short or simply because no method has been proposed for such a comparison.

The purpose of this paper is to select the physical parameters of a hailfall which better represent its severity, then to compute return periods for severe hailfalls, as is usually done for extreme events in meteorology and hydrology (Essenwanger, 1986). The hailpad data collected on the ANELFA network of southwestern France for 14 years will be used to test the method and to determine to what extent the results are dependent on the network density and extent.

\section{Hailfall severity parameters}

The parameters to be examined for return period analysis must be representative of the severity of hail damage to crops and other properties. They must also be easily measured by the most widely used types of hailpads. 
The diameter of the largest hailstone fallen on a pad, $D_{\max }$, is representative of damages to glasses, roofs, and cars, and is thus of primary concern for both urban and rural communities. It is also a key parameter in hailstorm dynamics and meteorological forecasting and will thus be considered first for the computing of return periods of severe hailfalls. However, this parameter is not the most appropriate one for the evaluation of crop damages. According to Changnon (1971a), the degree of loss to different types of crops can be better estimated either by the kinetic energy imparted by the total point hailfall, $E_{\text {tot }}$, or by the number of hailstones with diameters larger than $0.64 \mathrm{~cm}$ ( 0.25 in.), $N_{\text {tot }}$ One or both of these parameters relate well with crop loss values in all months of potential hail damage. $E_{\text {tot }}$ is now widely used to determine the severity of hailfalls, thus, we used it as the second parameter for computing return periods of severe hailfalls.

Both $D_{\max }$ and $E_{\text {tot }}$ can be obtained from the processing of the most widely used hail measuring system, which is based on the measurement of the dents left by the hailstones falling on a horizontal plate of extruded polystyrene (Lozowski and Strong, 1978). The system has been adopted by the ANELFA for the control of its hail prevention project with silver iodide ground generators. The hailpad material, the calibration and automatic data processing are described in Dessens and Fraile (1994) and Dessens et al. (2001). The date, time, and duration are known, and the number of hailstones is measured in 13 classes of dimension from $5 \mathrm{~mm}$ to $D_{\max }$ for each hailfall. The computation of $E_{\text {tot }}$ is made during the digital image analysis. The same system has also been adopted with a few minor changes for the ACMG, Spanish, and Italian networks.

According to the observations made, hailstones larger than those measured on a hailpad may be found on the ground around the hailpad site. During the "Grossversuch IV" Swiss project, Smith and Waldvogel (1989) compared maximum hailstone diameters measured on hailpads to those found by observers close to the corresponding hailpads. They concluded that the difference between the measured and observed diameters is of the order of one $\mathrm{cm}$, with the largest diameters for the observed data. This result, which is explained by the difference between the sampling areas of an observer and of a hailpad (Bardsley, 1990), must be remembered when using the $D_{\max }$ return periods computed from hailpad data.

\section{Overview of hail climatology in southwestern France}

The map of the hail risk in France (Vinet, 2001) shows that hail intensities and frequencies are the highest from the Pyrenees to the Rhône valley. This explains why a hail suppression program began in 1952 in the départements (administrative regions) of Aquitaine and was progressively extended to others. The ANELFA, which is a nonprofit association funded by administrative and professional organizations, carries on this program. Silver iodide seeding is operated from the ground by generators running from $3 \mathrm{~h}$ before the beginning until the end of the hail risk periods.

Hailpad networks were set up in nine départements of the southwestern area to study seeding efficiency beginning in 1981. The other départements (southeastern and central 
France) were only equipped later, the total number of hailpads is now 1083 (Fig. 1). Hence, the present study was limited to the southwestern area, composed of five départements along the Atlantic and four inland départements (Table 1). During the 1988-2001 hail seasons, exactly 3000 point hailfalls were recorded in the 777 stations (mean annual number) of these nine départements, and their data will be used for the climatology elements which follow.

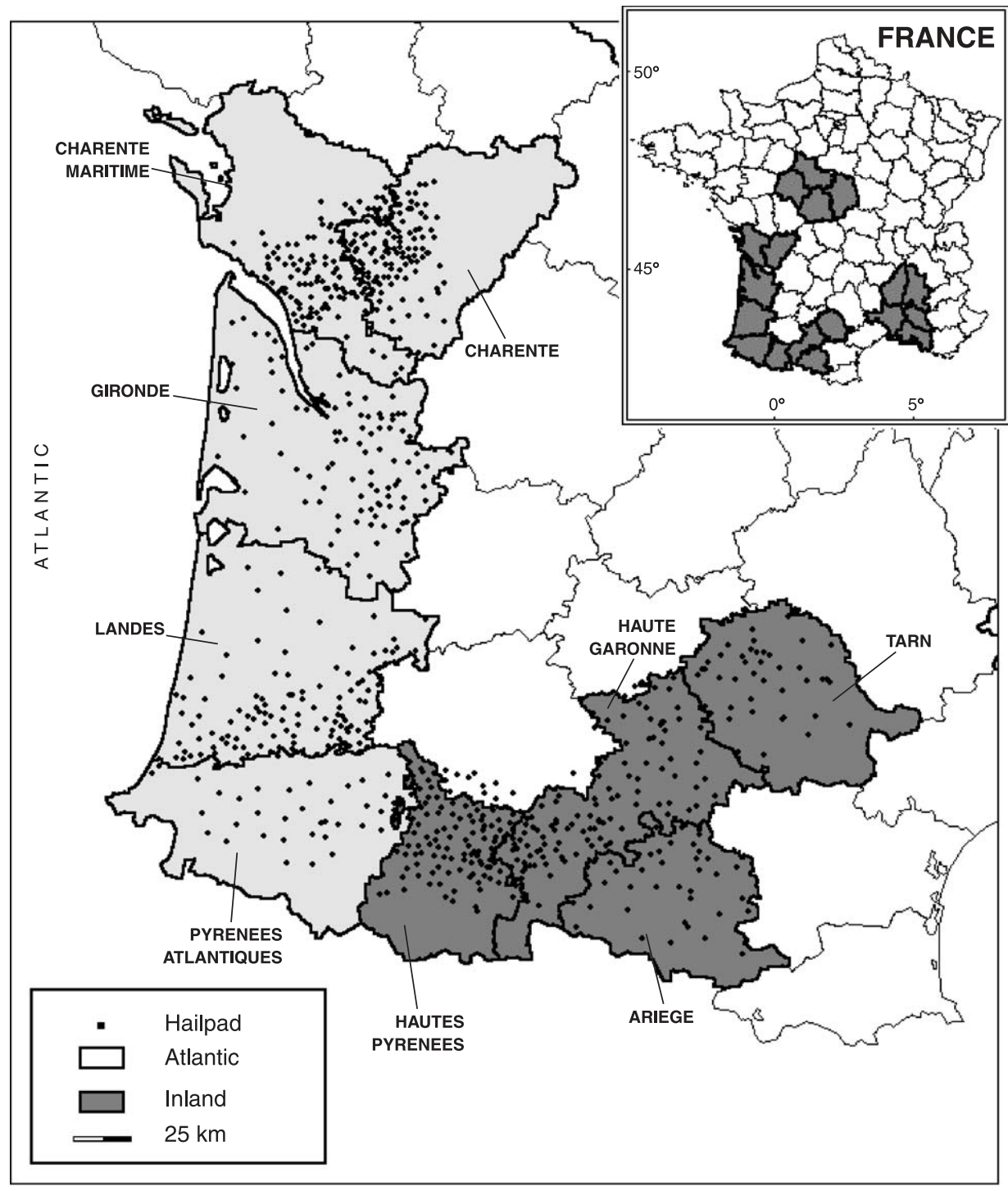

Fig. 1. Map of the ANELFA hailpad networks in France. 
Table 1

The ANELFA southwestern hailpad network

\begin{tabular}{llll}
\hline Region & département & $\begin{array}{l}\text { Network area } \\
\left(\mathrm{km}^{2}\right)\end{array}$ & $\begin{array}{l}\text { Number of } \\
\text { hailpad stations }\end{array}$ \\
\hline Atlantic & 16-Charente & 3000 & 120 \\
& 17-Charente-Maritime & 3000 & 111 \\
& 33-Gironde & 6000 & 100 \\
& 40-Landes & 4000 & 126 \\
& 64-Pyrénées-Atlantiques & 3000 & 23 \\
09-Ariège & 4000 & 40 \\
Inland & 31-Haute-Garonne & 5000 & 121 \\
& 65-Hautes-Pyrénées & 3000 & 127 \\
& 81-Tarn & 4000 & 43 \\
\hline
\end{tabular}

Areal extent and number of hailpad stations in 2001.

Fig. 2 gives the annual mean kinetic energy values of hailfalls per hailpad station on the nine-département area. Hail has suffered its usual variability during the 13-year period, with the well known-but still unexplained-alternation of about 3 years above average and 3 years under average. The mean monthly frequency of the total kinetic energy received on the nine-département area is given in Fig. 3. June is curiously flanked by 2 months with more hail, a result that deserves further investigation. Fig. 3 also gives the hourly frequency of the total kinetic energy, which peaks between 16 and 18 UTC (UTC is also solar time in the studied area), and which is zero around 06 UTC. The maximum frequency can be explained as follows: During a summer day, the maximum surface temperature occurs at around 16 UTC (Oke, 1978). Because the gestation time of a hailfall after the updrafts start from the ground is about 1 $\mathrm{h}$ (Dessens, 1998), it is logical to find a maximum frequency of hailfalls around 17 UTC.

Similar graphs (not given here) show that the mean annual values of $D_{\max }$ are well correlated with those of $E_{\text {tot }}$. The monthly mean values of $D_{\max }$ regularly increase from

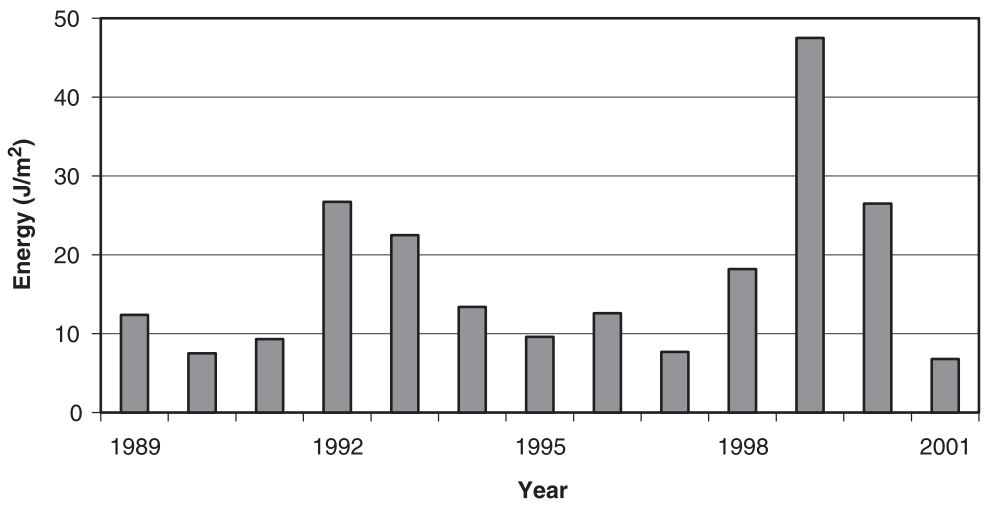

Fig. 2. Annual values of the mean point hailfall kinetic energy per hailpad station in the southwestern network. 

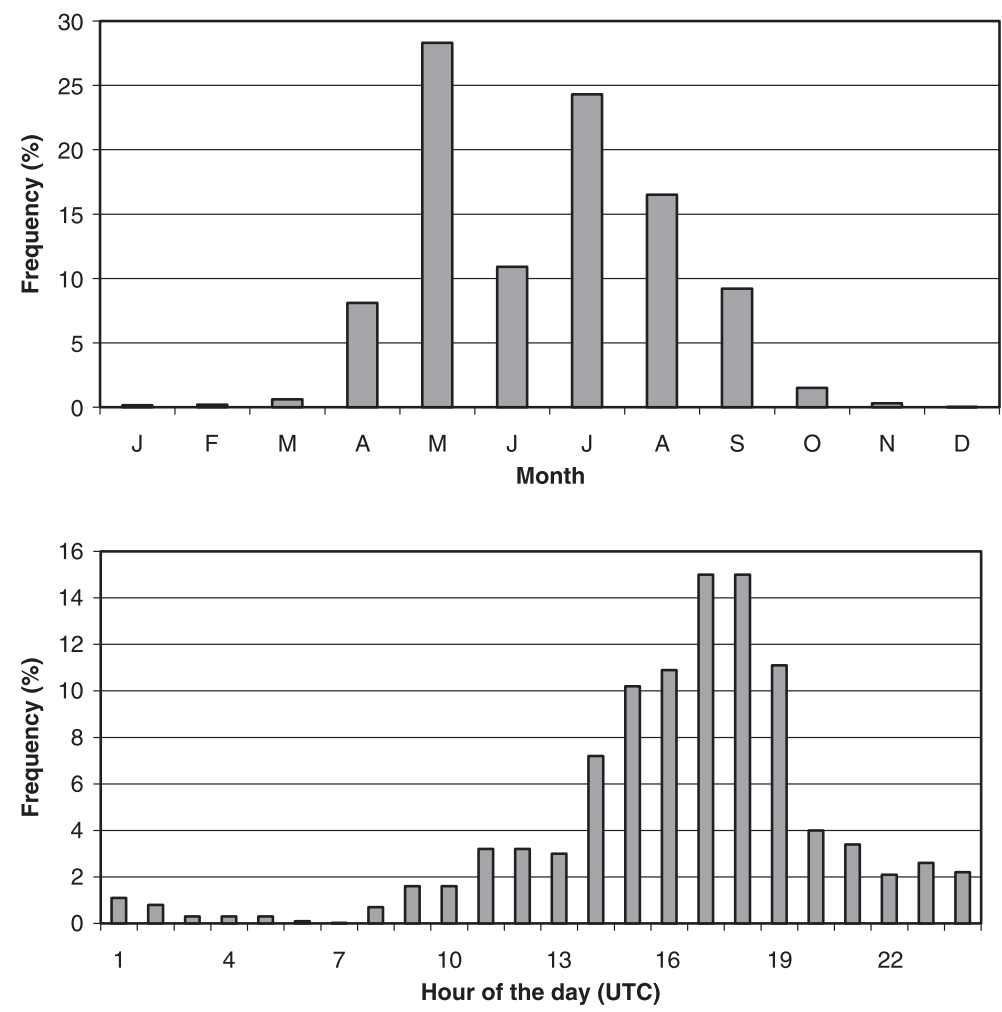

Fig. 3. Monthly and hourly frequencies (in percents) of the total kinetic energy of hailfalls during the 1989-2001 period in the southwestern network.

February $\left(D_{\max }=10.5 \mathrm{~mm}\right)$ to June $\left(D_{\max }=16.4 \mathrm{~mm}\right)$, then do not change significantly until October. The hourly mean values of $D_{\max }$ have a nearly constant value $(15-16$ $\mathrm{mm}$ ) from 7 to $24 \mathrm{UTC}$, then regularly decrease to a minimum value of $11.2 \mathrm{~mm}$ at 6 UTC.

\section{Return periods of severe hailfalls}

\subsection{The Gumbel distribution}

The computation of return periods for extreme events requires the use of probability density functions. The most widely used in meteorology is the Gumbel distribution (Sneyers, 1990). For example, this type of distribution has been applied in studies on icing loads on cables (Pezard, 1995), extreme drought episodes (Lana and Burgueno, 1998), and storm frequency analysis (Yue, 2000). The first type of Gumbel distribution is the FisherTippet distribution (Essenwanger, 1986), often called the Gumbel law because this 
scientist devoted much effort to the study of the properties of this particular distribution. Its probability density function is:

$$
f(z)=\exp [-z-\exp (-z)]
$$

which fulfills the condition of normalization:

$$
\int_{-\infty}^{+\infty} f(z) \mathrm{d} z=1
$$

It is a bell-shaped nonsymmetric curve with a peak at $z=0(f(0)=1 / \mathrm{e})$. The mean (first central moment) is 0.57721 (the $\gamma$ Euler's constant), and the variance (second central moment) is $\pi^{2} / 6$.

The distribution function (or cumulative distribution function) can be easily calculated as:

$$
F(z)=\int_{-\infty}^{z} f(y) \mathrm{d} y=\exp [-\exp (-z)]
$$

Sometimes, a change of variable is operated:

$$
z=\frac{x-a}{b}
$$

That is, a displacement (the peak is now at $x=a$ ) and a stretching (or contraction) of the bell; $a$ is called the location parameter (the mode) and $b$ the scale parameter. Due to the condition of normality, the new probability density function becomes:

$$
f(x)=\frac{1}{b} \exp \left[-\frac{x-a}{b}-\exp \left(-\frac{x-a}{b}\right)\right]
$$

This shape of the Gumbel probability density function is more common in studies on extreme hydrologic data. In order to calculate the values of $a$ and $b$, several methods can be used, such as the method of moments and the maximum likelihood estimator method. The method of moments estimates the first two moments of the distribution from the mean and variance of the sample. The maximum likelihood method, based on the most probable values of the parameters, is more efficient than the method of moments (Essenwanger, 1986). Nevertheless, iterative procedures are required to solve the equations from which estimators are obtained.

At first, the parameters were calculated following both methods, but two facts clearly appeared:

- The results (the values of the parameters $a$ and $b$ ) are similar in most of the cases for both methods.

- When applying the goodness of fit Kolmogorov-Smirnov test, the distribution functions calculated with both methods fit well for a significance level of 0.05 .

After considering these results, only the parameters given by the method of moments, easier to apply, were finally calculated (and retained). 
Table 2

Annual values of the maximum hailfall kinetic energy $\left(\mathrm{J} / \mathrm{m}^{2}\right)$ measured in the Atlantic and inland hailpad networks

\begin{tabular}{|c|c|c|c|c|c|c|c|c|c|}
\hline \multirow[t]{2}{*}{ Year } & \multicolumn{5}{|c|}{ Atlantic } & \multicolumn{4}{|c|}{ Inland } \\
\hline & 16 & 17 & 33 & 40 & 64 & 09 & 31 & 65 & 81 \\
\hline 1987 & & & & & & & 496 & & \\
\hline 1988 & & 37 & 0 & 13 & & & 508 & 466 & \\
\hline 1989 & 93 & 381 & 122 & 326 & 108 & & 1227 & 429 & 36 \\
\hline 1990 & 122 & 284 & 104 & 168 & 143 & & 215 & 249 & 159 \\
\hline 1991 & 31 & 102 & 308 & 309 & 148 & 0 & 452 & 435 & 125 \\
\hline 1992 & 334 & 43 & 622 & 1005 & 92 & 412 & 844 & 1654 & 1181 \\
\hline 1993 & 164 & 179 & 94 & 492 & 160 & 67 & 341 & 723 & 266 \\
\hline 1994 & 118 & 36 & 30 & 93 & 88 & 465 & 1248 & 234 & 160 \\
\hline 1995 & 30 & 5 & 120 & 147 & 9 & 0 & 357 & 917 & 675 \\
\hline 1996 & 34 & 58 & 73 & 619 & 26 & 497 & 501 & 292 & 464 \\
\hline 1997 & 40 & 43 & 64 & 1243 & 35 & 107 & 261 & 315 & 152 \\
\hline 1998 & 102 & 66 & 79 & 393 & 157 & 268 & 961 & 447 & 1017 \\
\hline 1999 & 258 & 12 & 362 & 916 & 415 & 512 & 1429 & 1210 & 277 \\
\hline 2000 & 745 & 80 & 100 & 238 & 344 & 76 & 564 & 777 & 228 \\
\hline 2001 & 19 & 153 & 140 & 11 & 305 & 0 & 392 & 248 & 69 \\
\hline
\end{tabular}

The time necessary for an extreme value to recur is often called the return period, which is defined as:

$$
T(z)=\frac{1}{1-F(z)}
$$

where $F(z)$ has the time unit selected to determine the extreme data. Another interesting parameter is the probability of recording, during a year, the biggest hailstone of a certain

Table 3

Same as Table 1 but for the diameter $(\mathrm{mm})$ of the largest hailstones

\begin{tabular}{|c|c|c|c|c|c|c|c|c|c|}
\hline \multirow[t]{2}{*}{ Year } & \multicolumn{5}{|c|}{ Atlantic } & \multicolumn{4}{|c|}{ Inland } \\
\hline & 16 & 17 & 33 & 40 & 64 & 09 & 31 & 65 & 81 \\
\hline 1987 & & & & & & & 26 & & \\
\hline 1988 & & 11 & 7 & 13 & & & 36 & 15 & \\
\hline 1989 & 16 & 18 & 14 & 24 & 14 & & 41 & 40 & 15 \\
\hline 1990 & 29 & 24 & 21 & 25 & 17 & & 21 & 25 & 13 \\
\hline 1991 & 17 & 18 & 28 & 33 & 26 & 10 & 27 & 36 & 20 \\
\hline 1992 & 27 & 12 & 28 & 32 & 22 & 26 & 29 & 41 & 30 \\
\hline 1993 & 19 & 28 & 16 & 35 & 30 & 16 & 27 & 37 & 25 \\
\hline 1994 & 31 & 12 & 13 & 19 & 16 & 31 & 44 & 22 & 20 \\
\hline 1995 & 17 & 7 & 17 & 25 & 21 & 0 & 26 & 40 & 27 \\
\hline 1996 & 13 & 12 & 18 & 34 & 13 & 39 & 20 & 26 & 38 \\
\hline 1997 & 14 & 12 & 18 & 40 & 15 & 17 & 20 & 14 & 17 \\
\hline 1998 & 13 & 15 & 17 & 23 & 23 & 26 & 33 & 23 & 33 \\
\hline 1999 & 21 & 9 & 22 & 33 & 29 & 23 & 35 & 45 & 24 \\
\hline 2000 & 27 & 16 & 19 & 21 & 34 & 15 & 24 & 35 & 27 \\
\hline 2001 & 11 & 19 & 23 & 8 & 18 & 0 & 27 & 16 & 16 \\
\hline
\end{tabular}




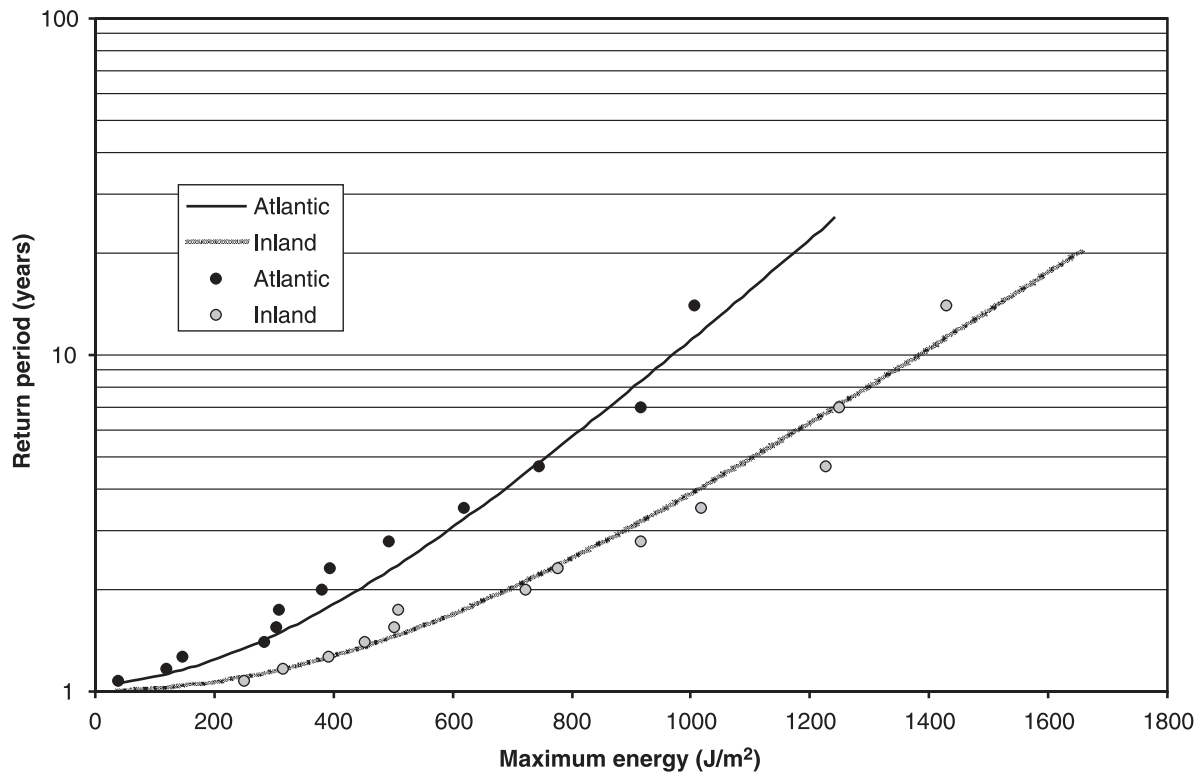

Fig. 4. Return periods (in years) of point hailfalls of maximum kinetic energy for the Atlantic and inland regions, computed from the Gumbel distribution (solid lines). The experimental data are also plotted.

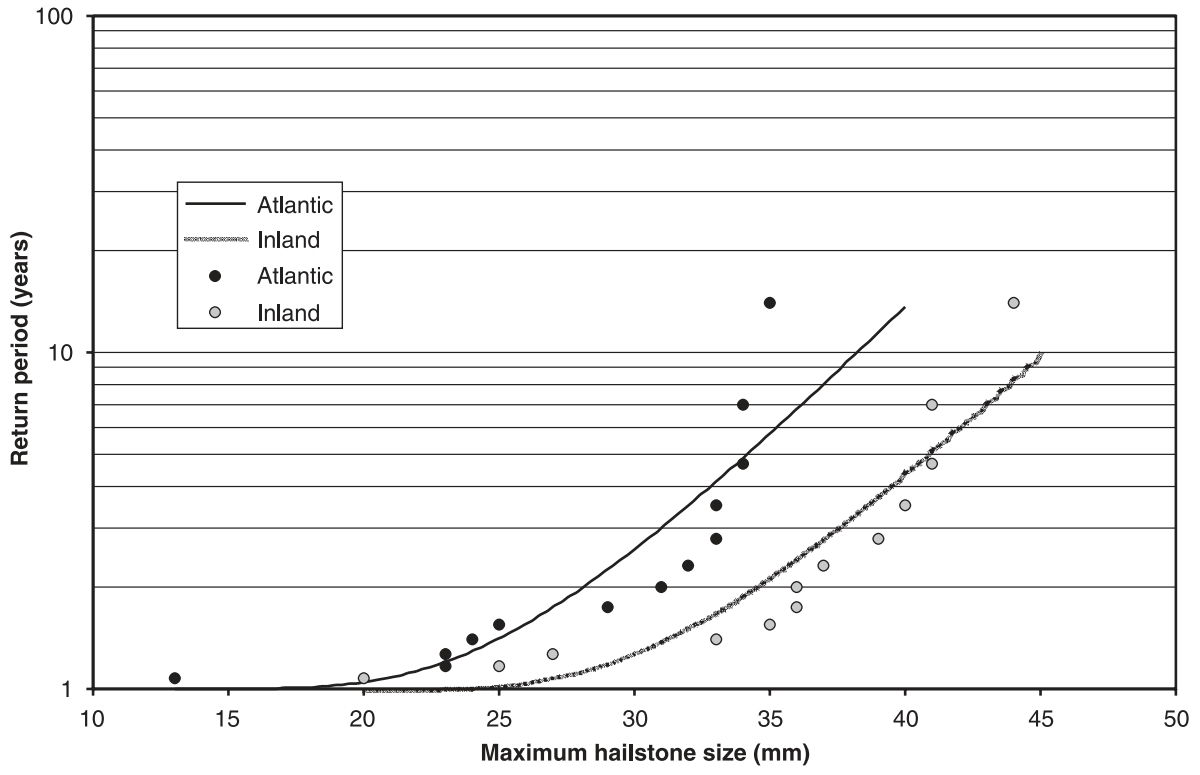

Fig. 5. Same as Fig. 4 but for large hailstones (diameter of $30 \mathrm{~mm}$ or more). 
Table 4

Return periods (years) of hailfalls with kinetic energy of $500 \mathrm{~J} / \mathrm{m}^{2}$ or more, or with large hailstones (diameter of $30 \mathrm{~mm}$ or more) in six départements having similar hailpad network disposition

\begin{tabular}{llllllll}
\hline & \multicolumn{2}{l}{ Atlantic } & & & \multicolumn{2}{c}{ Inland } \\
\cline { 2 - 8 } \cline { 3 - 7 } & 16 & 17 & 33 & 40 & 31 & 65 \\
\hline$E_{\text {tot }} \geq 500 \mathrm{~J} \mathrm{~m}^{-2}$ & 16 & $>40$ & 25 & 3.0 & 1.5 & 1.0 \\
$D_{\max } \geq 30 \mathrm{~mm}$ & 14 & $>30$ & $>20$ & 3.5 & 2.5 & 2.5 \\
\hline
\end{tabular}

size. This probability is called the risk of occurrence, and it is defined as the reverse of the return period:

$$
R=1 / T(z)=1-F(z)
$$

\subsection{Results}

Tables 2 and 3 give the annual maximum values of $E_{\text {tot }}$ and $D_{\max }$ in each département equipped with a hailpad network. A former climatological study of hail in southwestern France has shown that the Atlantic and inland regions should be considered separately (Dessens, 1986). In Figs. 4 and 5, the curves show the return periods of hailfalls for $E_{\text {tot }}$ and $D_{\max }$, as calculated from the Gumbel distribution. The return periods $T(z)$ for each datum $z$, also represented in these figures, are calculated as follows: $T(z)=S /(S-s)$ where $S$ is the sample size (the total number of years considered) and $s$ is the number of years in which the maximum value recorded is below $z$ or equal to it. Because the two regions have about the same extent and hailpad density, an immediate comparison is possible between them, and it shows that return periods of very severe hailfalls are nearly three times shorter in the inland area.

It is possible to compare return periods in six départements having approximately the same hailpad disposition in extent and density. As an example of results, Table 4 gives the return periods of very severe hailfalls $\left(E_{\mathrm{tot}} \geq 500 \mathrm{~J} \mathrm{~m}^{-2}, D_{\max } \geq 30 \mathrm{~mm}\right)$. A ranking of the départements gives, from the most to less hailed ones: 65-Hautes-Pyrénées, 31-HauteGaronne, 40-Landes, 16-Charente, 33-Gironde, and 17-Charente-Maritime. The hail risk is then maximum just downwind of the highest part of the Pyrenees, which confirms the frequency map drawn by Vinet (2001).

\section{Effects of hailpad network density and extent}

The return periods computed in the last section are relative to specific hailpad networks, and it is necessary to determine in what ways these results are influenced by the number of hailpad stations per network and by the geographical extent of the network area. These effects of hailpad network density and extent will be illustrated for $D_{\max }$ only. 


\subsection{Network density}

Haute-Garonne is the département where the hailpad stations have been in operation for the largest number of years. The number of stations in this département has slightly increased, from 96 in 1987 to 121 in 2001, with a mean annual value of 109. The hailpad stations are regularly distributed over an area of about $5000 \mathrm{~km}^{2}$. The effect of a change in the network density on the return periods was tested by calculating the daily maximum hailstone size for this département (31-Haute-Garonne), taking into account $80 \%$ and $60 \%$ of the whole hailpad network, successively. For each percentage, $P$, the daily maximum hailstone size was calculated by considering all the possible subsets of $\mathrm{n}$ hailpads, where $n=P N / 100$, and $N$ is the total number of hailpads. For each subset, the annual maximum hailstone size recorded by the $\mathrm{n}$ hailpads was retained, and the mean of all the possible subsets calculated (that is, the expected maximum hailstone size for a percentage $P$ ). This last parameter was considered as the annual maximum hailstone size for that percentage $P$. The calculations were repeated for the two percentages, and the return periods for each percentage calculated by the method of moments (Fig. 6).

Return periods for percentages higher than 100 can be extrapolated from the curves that give the maximum hailstone size as a function of the percentage of hailpads. For example, fitting a curve with a horizontal asymptote, the annual maximum hailstone size for a hypothetical hailpad network of $2 N$ hailpads $(200 \%)$ was determined. With these data, the

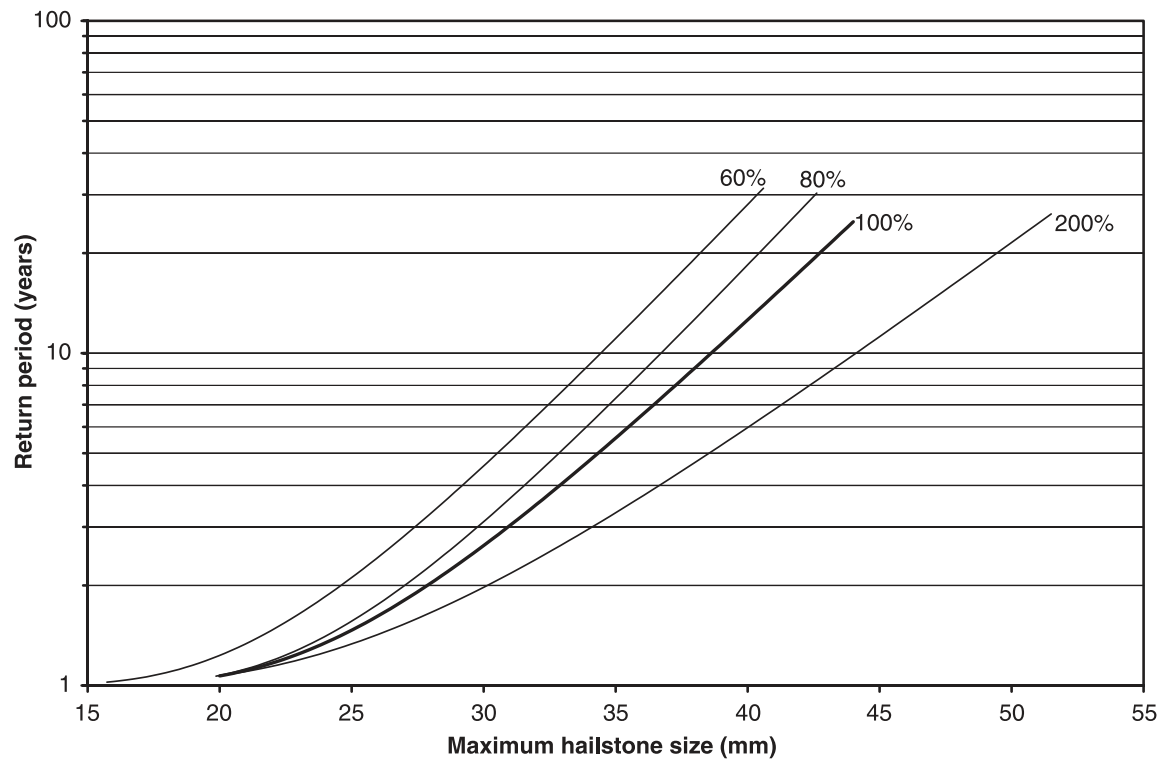

Fig. 6. Return periods of hailfalls of given large hailstones (diameter of $30 \mathrm{~mm}$ or more) in the network of 31 Haute-Garonne. 100\%: Real data, 109 hailpad stations $/ 5000 \mathrm{~km}^{2} .80 \%$, 60\%: Simulation with less hailpad stations. 200\%: Simulation with double hailpad stations. 
calculation of the return periods was easily made by applying the method of moments (Fig. 6).

The "200\%" curve of Fig. 6 suggests that the density of the present network (one hailpad per $46 \mathrm{~km}^{2}$ ) leads to overestimated return periods. This probably means that the scale of hailfalls is sometimes lower than the scale of the hailpad network. Changnon (1977) found that the smallest hail entity - the hailstreak - has a median size of $20.5 \mathrm{~km}^{2}$ in central Illinois, which is probably not very different from the size found in southwestern France. However, the largest and most severe hail entity - the hailswath - can certainly be captured by the ANELFA network, because its size in southwestern France averages 540 $\mathrm{km}^{2}$ (Dessens, 1986).

\subsection{Network extent}

The effect of the network extent on the return periods is obvious, and it would be extremely useful to (i) establish a relationship between the return period and the network area, and (ii) compute return periods at a point from return periods on a given area. Changnon (1971b) examined a similar problem for the determination of area hail frequencies, given point frequencies. Using data of dense hail networks of varying sizes in Illinois and of one in Colorado, he derived a regression equation that estimated the ratio of the area hail-day frequency, $F_{\mathrm{A}}$ (in years ${ }^{-1}$ ), to the point hail frequency, $F_{\mathrm{P}}$ (in years $^{-1}$ ), as a function of the area size, $A$ :

$$
\ln \left(F_{\mathrm{A}} / F_{\mathrm{P}}\right)=0.058+0.313 \ln A, \quad \text { with } A \text { in } \mathrm{mi}^{2}
$$

or, after standardization of the surface unit:

$$
\ln \left(F_{\mathrm{A}} / F_{\mathrm{P}}\right)=-0.240+0.313 \ln A, \quad \text { with } A \text { in } \mathrm{km}^{2}
$$

Eq. (2) gives $F_{\mathrm{A}}=F_{\mathrm{P}}$ for $A=2.15 \mathrm{~km}^{2}$, which implies that the scale of a hailfall is of about $1 \mathrm{~km}$. Considering that Eq. (2) is also valid for severe hail-day frequencies, it can be applied to return periods in networks of different areas. A return period being the inverse of a frequency, Eq. (2) gives:

$$
\ln \left(T_{\mathrm{P}} / T_{\mathrm{A}}\right)=-0.240+0.313 \ln A,
$$

where $T_{\mathrm{P}}$ and $T_{\mathrm{A}}$ are respectively the point and area return periods (in years) for an area of size $A$ (in $\mathrm{km}^{2}$ ). The point return periods can then be computed by multiplying the area return periods respectively by 17.2 and 16.3 for the Atlantic $\left(19,000 \mathrm{~km}^{2}\right)$ and inland $\left(16,000 \mathrm{~km}^{2}\right)$ regions, and by 11.3 for the département 31 -Haute-Garonne $\left(5000 \mathrm{~km}^{2}\right)$. As an example, the point return period of $D_{\max }=30 \mathrm{~mm}$ measured (or $40 \mathrm{~mm}$ observed) is found to be 22 years in the inland area, 29 years in the département 31-Haute-Garonne, and 50 years in the Atlantic area.

Changnon (1971b) noted that the area-point relationships appear to have little geographical difference within the United States. However, it is not sure that they are 
also valid in southwestern France. More years of measurements and more studies are necessary to confirm this very preliminary evaluation of a point return period.

\section{Conclusion}

A damaging hailfall at the ground is a rare and erratic phenomenon, even in countries known for their high risk of hail damage. Climatological studies of this type of precipitation require many years of measurements. Southwestern France is one of the few places in the world where such measurements have been continuously made since 1988-1989, and the data can now be processed for middle-term climatological studies. The method proposed in this paper is adapted from the determination of return periods in hydrology and other fields of meteorology. Two parameters have been selected for determining the intensity of a point hailfall: the total kinetic energy of the hailstones, $E_{\mathrm{tot}}$, and the diameter of the largest hailstones, $D_{\max }$. The Gumbel distribution has been used to represent the probability density function of the maximum annual value of these two parameters.

The 3000 point hailfall data set recorded by the ANELFA for 14 years over an extensive hailpad network of 777 stations (mean number for the period) scattered over a $35,000 \mathrm{~km}^{2}$ area of southwestern France gives the following main results:

1. Very severe hailfalls $\left(E_{\mathrm{tot}} \geq 500 \mathrm{~J} \mathrm{~m}^{-2}, D_{\max } \geq 30 \mathrm{~mm}\right.$ ) are three times more frequent in the southern départements north of the central Pyrenees than in the northern départements along the Atlantic coast.

2. In the most hailed département of 65-Hautes-Pyrénées, the return period is 2.5 years for a $E_{\text {tot }}=500 \mathrm{~J} \mathrm{~m}^{-2}$ hailfall, and 1.0 year for a $D_{\max }=30 \mathrm{~mm}$ hailfall (Table 4). However, this value of $D_{\max }$ should be increased to $40 \mathrm{~mm}$ to take into account the common observation that the largest hailstones fallen around a hailpad are about $10 \mathrm{~mm}$ larger than those measured.

3. The simulation of a decrease in the present hailpad network density suggests that an average of one hailpad per $40 \mathrm{~km}^{2}$ leads to overestimated values for severe hailfall return periods. More years of measurements are needed to determine the optimal density or the correcting factors.

4. According to observations made by Changnon (1971b) in the US, there should be a relationship between area and point hailfall return periods. A preliminary estimation, based on area-point frequency ratios observed in the US, indicates for example that the risk of hailstones larger than $30-40 \mathrm{~mm}$ at a point of the inland area is of one hailfall per 22 years. Such a result will not be a surprise to the people living there, and it explains why hail is a significant meteorological problem in this region.

The determination of return periods of severe hailfalls in different countries of Europe could constitute a useful tool for research and in several economic areas, including insurance industry, hailstorm physics, forecasting, and weather and climate modification. However, such a determination will require many years of continuous hailpad measurements on extended areas. 


\section{Acknowledgements}

The authors express their gratitude to Didier Dutrey and to Eduardo Garcia Ortega for their contribution in collecting and processing the hailpad data. They also wish to thank the anonymous reviewers for the valuable comments that helped improve the manuscript.

\section{References}

Admirat, P., Goyer, G.G., Wojtiw, L., Carte, E.A., Roos, D., Lozowski, E.P., 1985. A comparative study of hailstorms in Switzerland, Canada and South Africa. J. Climatol. 5, 35-51.

Bardsley, W.E., 1990. On the maximum observed hailstone size. J. Appl. Meteorol. 29, 1185-1187.

Changnon, S.A., 1971a. Hailfall characteristics related to crop damage. J. Appl. Meteorol. 10, 270-274.

Changnon, S.A., 1971b. Means for estimating areal hail-day frequencies. J. Weather Modif. 3, 154-159.

Changnon, S.A., 1977. The scales of hail. J. Appl. Meteorol. 16, 626-648.

Dessens, J., 1986. Hail in southwestern France: I. Hailfall characteristics and hailstorm environment. J. Clim. Appl. Meteorol. 25, 35-47.

Dessens, J., 1998. A physical evaluation of a hail suppression project with silver iodide ground burners in southwestern France. J. Appl. Meteorol. 37, 1588-1599.

Dessens, J., Fraile, R., 1994. Hailstone size distributions in southwestern France. Atmos. Res. 33, 57-73.

Dessens, J., Fraile, R., Pont, V., Sanchez, J.L., 2001. Day-of-the-week variability of hail in southwestern France. Atmos. Res. 59-60, 63-76.

Essenwanger, O.M., 1986. Elements of Statistical Analysis. General Climatology, vol. 1B. Elsevier, Amsterdam. $424 \mathrm{pp}$.

Fraile, R., Sanchez, J.L., de la Madrid, J.L., Castro, A., Marcos, J.L., 1999. Some results from the hailpad network in León (Spain): noteworthy correlations among hailfall parameters. Theor. Appl. Climatol. 64, $105-117$.

Genève, G., 1961. La Grêle. Météorologie Nationale, Mémorial No. 48.75 pp., Available from Météo-France, 2 Avenue Rapp, 75340 Paris Cedex 07, France.

Giaiotti, D., Gianesini, E., Stel, F., 2001. Heuristic considerations pertaining to hailstone size distributions in the plain of Friuli-Venezia Giulia. Atmos. Res. 57, 269-288.

Hohl, R., Schiesser, H.H., Aller, D., 2002. Hailfall: the relationship between radar-derived hail kinetic energy and hail damage to buildings. Atmos. Res. 63, 177-207.

Lana, X., Burgueno, A., 1998. Spatial and temporal characterization of annual extreme droughts in Catalonia (Northeast Spain). J. Climatol. 18, 93-110.

Lozowski, E., Strong, G.S., 1978. On the calibration of hailpads. J. Appl. Meteorol. 17, 521-528.

Oke, T.R., 1978. Boundary Layer Climate. Methuen, London. 424 pp.

Pezard, J., 1995. A method to estimate icing loads on overhead lines. Atmos. Res. 36, 303-310.

Plumandon, J.R., 1901. Les Orages et la Grêle. Masson et Cie, Ed, Paris. 192 pp.

Smith, P.L., Waldvogel, A., 1989. On determinations of maximum hailstone sizes from hailpad observations. J. Appl. Meteorol. 28, 71-76.

Sneyers, R., 1990. On the Statistical Analysis of Series of Observations. WMO Tech. Note 143, Geneva, 192 pp.

Vinet, F., 2000. Le Risque-Grêle en Agriculture. Technique et Documentation, Paris. 237 pp.

Vinet, F., 2001. Climatology of hail in France. Atmos. Res. 56, 309-323.

Yue, S., 2000. The Gumbel mixed model applied to storm frequency analysis. Water Resour. Manag. 14, 377-389. 